\title{
La lucha de la mujer en México. Un fenómeno descubridor (1970-1983)
}

María Inés Garcia C. Ana LauJ.

Quien se cree capaz de separar su mundo interno del mundo exterior, no tiene ningún mundo interno del cual pueda separar nada.

Elias Canetti

$\boldsymbol{A}$ sistimos en la última década a una serie de cambios en el plano de la práctica y del pensamiento que nos parecen incomprensibles a la luz de los patrones de análisis conocidos.

La crisis aparece evidente en el plano de lo económico; tiene también manifestaciones claras en lo político: surgen nuevas formas de agrupamiento de los sujetos, luchas diferentes a las conocidas, movilizaciones que no encuadran dentro de los cánones establecidos e institucionalizados.

Somos protagonistas de esta época de crisis en el más amplio sentido: cambio de concepciones, quiebre de teorias, experiencias que declinan, utopías que se desintegran, nuevos sentimientos que emergen, situaciones que desbordan el análisis, prácticas sociales nuevas, formas distintas de subversión del orden establecido.

La cotidianeidad adquiere un papel trascendental, aquello a lo que se le reservaba el rótulo de privado, de personal, de irrelevante en el plano social, comienza a adquirir un status político y social, encontrándonos sin categorías para su análisis. La teória social presenta en estos momentos evidentes lagunas en su función explicativa; no abarca este tipo de fenómenos.

En este contexto aparecen los nuevos movimientos sociales, generalmente de carácter urbano, de luchas parcializadas, realizando prácticas que controvierten el orden social dominante a partir de contradicciones específicas que afectan de manera directa a grupos determinados. Socavan, a través de la crítica y la reivindicación concreta, los cimientos de ese orden aún sin proponérselo. sin un objetivo consciente. Luchan por objetivos parciales, resisten porque sienten en sí mismos la opresión y el sometimiento, exigen un espacio, alzan una voz, hacen política.

Surgen de esta manera nuevas formas de conflictos sociales ligados directamente a la organización de la vida cotidiana, caracterizados por la elaboración de un discurso alternativo al dominante y diferenciado del discurso de las clases dominadas emitido por sus instancias organizativas (partidos, sindicatos, etc.). Van desarrollando lenta, fragmentaria y focalmente un saber-otro, un saber local calificado de inferior en relación al conocimiento científico y "es a través de estos saberes locales de la gente, de estos saberes descalificados, como se ha operado la crítica"."

Estos movimientos no son de carácter general y centralizado sino que atacan el orden por distintos flancos, luchan contra el poder dominante allí donde se manifiesta en su acontecer diario, en su ámbito cotidiano.

En esta perspectiva podemos ubicar al movimiento feminista. Mujeres que se agrupan para luchar contra la forma en que se expresa el dominio y el sometimiento en sus propios cuerpos, en su sexualidad, en sus relaciones, en

1 Michel Foucault, Microfísica del poder. Madrid. Ediciones de la Piqueta, 1979, (Col. Genealogía del Poder). p. 129 
lo que tiene de sometido lo más personal, lo más vital, no resignándose a invocar la sociedad ideal del mañana como forma de consuelo de sus propias miserias.

Es una lucha específica, que sólo les atañe en tanto mujeres; fragmentaria, sin intención de globalización ni universalidad; el objetivo es luchar contra todas las formas de manifestación del poder. "Aquí, el enemigo cambia de rostro: es posible que llegue a ser el aliado, el compañero, el responsable. o bien uno mismo", ${ }^{2}$ por lo tanto no es una lucha que pueda ser realizada por intermedio de "delegados" o "representantes" sino que es tarea de cada una de ellas llevarla a sus propias filas y dirigirla contra los valores impuestos y enraizados en su fuero interno, contra toda posible complicidad inconsciente.

Esto explica su funcionamiento: la necesidad de grupos de concientización. "dar la palabra a las mujeres", quienes a través de la explicitación de su propia vida y la confrontación de experiencias clarifican las formas en que se expresa el sometimiento y la dominación; y la defensa de la autonomía del movimiento. es decir, no aparecer como el apéndice de una organización de hombres.

Esta subversión de la vida cotidiana, este ir contra la identidad que los cánones establecidos le exigen a la mujer, es una lucha específica contra el poder que da significación al lema "lo personal es político".

Adquiere relevancia un problema teórico. No se realiza una conceptualización del poder de carácter descendente, en la que la lucha iría dirigida hacia los centros de emergencia del poder, el Estado. La crítica es horizontal y ascendente, desde sus manifestaciones más cotidianas hasta las formas en que circula y se imbrica en el cuerpo social.

El poder será considerado como una relación de fuerza y analizado en términos de lucha y enfrentamiento. de allí que estos planteamientos conduzcan a un tratamiento de la dominación no desde una perspectiva global, sino desde las múltiples formas de dominación, de sometimiento y sujeción, es decir, un análisis de los sujetos en sus relaciones recíprocas.

De esta manera la lucha parece dirigida en contra de los hombres. El hecho es que el poder no flota en el aire, se encarna en sujetos y se lucha contra estos sujetos, contra el hombre como detentador del poder y no por el hecho de ser hombre. ${ }^{3}$

Un elemento de importancia respecto al movimiento feminista consiste en la elaboración lenta, paulatina, con marchas y contramarchas, de un discurso alternativo al dominante, discurso que pone en duda los valores aceptados al mismo tiempo que establece quiebres, puntos de fractura en el mismo, desmitificando imágenes y poniendo en tela de juicio papeles reconocidos.

Sin negar la diferencia entre los sexos, el discurso pugna por la igualdad, lo que lleva a descubrir en sus diferentes facetas la situación de opresión y sometimiento.

En este proceso, las mujeres vạn desarrollando, como lo hemos señalado. un saber focal que surge del hecho de "tomar la palabra", palabra que había sido callada y opacada durante siglos. Es el proceso de recuperación de su propia historia y del conocimiento de su propio cuerpo, su propia función, su estar en la sociedad.

2 Gilles Deleuze y Félix Guattari, Politica y Psicoanálisis México, Editorial Terra Nova, 1980. (Col. Interdisciplina). p. 12 (subrayado en el texto).

${ }^{3}$ Cfr., Eli Bartra, Desde el Traspatio. Ponencia presentada en el Coloquio "Balance del Sexenio". Acapulco. Gro., marzo 1982, p. 15. 
No fue éste un proceso ni lineal ni evolutivo, sino uno lento, complejo. y aún en producción, en el que se puede observar que en muchas ocasiones el mismo discurso y su práctica, quedaron entrampados en los valores dominantes, sin poder escapar de ellos. Es el caso de los contenidos evidentemente sexistas en algunos; en vez de luchar contra el poder y sus manifestaciones se luchaba por el poder y pasar asi de sometidas a sometedoras (reproducción de la lógica amo-escłavo). Algo semejante ocurrió con los contenidos plañideros del discruso, que llevan implícita la negación de la diferencia y un deseo de ocupar el lugar del dominador.

La lenta elaboración a través de este discurso, a veces contradictorio. de una nueva imagen de mujer, partió de un conocimiento de lo no querido hacia la búsqueda de un nuevo femenino y una inserción diferente en la sociedad que conlleva a una transformación de las relaciones interpersonales $y$ por lo tanto a la construcción de un nuevo mito en el plano de to simbólico. Proceso no acabado, tarea a la cual se hallan abocadas.

El riesgo que se corre es que ese saber subvertivo del orden, que guarda en sí la memoria de los enfrentamientos, puede ser recuperado y aún más. colonizado.

A pesar de ello, ese discurso feminista, fragmentario, localizado, focal, discontinuo y a veces contradictorio, ha exigido aun sin proponérselo, la revisión de los dos cuerpos teóricos más importantes del último siglo: el marxismo y el psicoanálisis.

Mostró de manera fehaciente las lagunas del marxismo en cuanto al papel de la mujer en el proceso de reproducción de la fuerza de trabajo y en la falta de categorías para analizar la vida cotidiana y sus procesos. Se realizaron y se realizan intentos por salvar estas carencias a través de la elaboración de conceptos tales como modo de producción doméstico, el trabajo doméstico de las mujeres, trabajo no retribuido, etcétera.

Por otro lado, el psicoanálisis puso en evidencia que la mujer no era objeto de tratamiento en esta disciplina; aparecía la madre y el hombre, o bien "lo hombre" $y$ "lo mujer" como ingredientes que rellenan un envase hombre o un envase mujer. Los análisis de la mujer se realizan a través de un discurrir netamente masculino, o a partir de lo que sucede en el hombre. El hecho que la mujer desaparezca tras la denominación ser humano, muestra que es necesario elaborar categorías diferenciadas que den cuenta de la realidad, dividida en hombres y mujeres.

Es evidente que la mujer no existe en el plano de lo pensado, no tenemos categorías de análisis para abordar su estudio, es Madre o es Hombre en sentido genérico. Pensar a la mujer es llevarla al plano de lo irracional, de lo mítico, de la magia, de la brujeria, del aquelarre...

Esta problemática presenta un amplio desafío tanto en el plano de lo teórico como de lo metoadológico y evidencia un espacio de trabajo aún no iniciado.

El feminismo en México, como en todo el mundo, es un fenómeno de origen urbano. Por tanto, los grupos de mujeres que se forman, lo hacen a partir de su identificación social y de la opresión que sienten en razón de su sexo. para luchar en contra de la enajenación que las tiene sojuzgadas.

El surgimiento de los diversos grupos de liberación femenina es de gran importancia por la denuncia que hacen "de la hipocresía abierta o sutil, de las mil formas de menospreciar a las mujeres". 4

Los grupos de liberación femenina no se dan espontáneamente, es el re-

4 Samir Amin et. al., "Femenismo y lucha de clases" en Samir Amin, Elogio de/ Socialismo y otros escritos, Barcelona, Editorial Anagrama, 1975, p. 110. 
sultado de varios factores a través de los cuales las mujeres toman conciencia de la opresión de que son objeto y la revierten como una lucha política:

a) la entrada de mujeres al mercado laboral por las necesidades del capitalismo:

b) la mayor participación de la mujer en la educación superior:

c) el desarrollo de métodos anticonceptivos baratos y eficientes, y

ch) el surgimiento de movimientos sociales y de masas durante los años sesenta.

Las mujeres comenzaron a analizar su papel en la sociedad y sus condiciones específicas de opresión, al igual que la necesidad de su alteración significativa. La conciencia femenina se transforma profundamente, y las lleva a actuar más allá del ámbito privado, hacen política. Convertirse en feminista implica el desarrollo de una nueva conciencia de sí misma, de los demás y de la realidad social.

Adquirir la conciencia feminista no es fácil, hay que reunirse con las demás mujeres y analizar la situación de opresión y sumisión de cada una, su vida personal; y es asi como se desarrolla el "pequeño grupo" como una forma de organización básica del movimiento. Por medio de las pláticas entre ellas, las mujeres se dan cuenta que la situación de opresión es general; de lo personal, se pasa a lo político: surge la conciencia feminista.

El lema feminista "Lo personal es político" y la importancia dada a la subversión de la vida cotidiana, genera una modificación en la perspectiva de la izquierda y da una visión más completa de lo que significa el quehacer transformador. Con este lema movilizador deja de tener vigencia la distinción entre vida privada y vida pública, exigiendo mayores niveles de coherencia en los comportamientos humanos.

Revolucionar la vida cotidiana significa la lucha diaria en todos los frentes donde las mujeres se encuentren, sean de ámbito privado o público, es la militancia como forma de vida, al tiempo que exige una actitud crítica constante de todo tipo de relación para luchar contra la forma en que el poder y la sumisión se expresen.

Los contenidos patriarcales y sus prácticas no terminan con la sociedad capitalista. Frente a esta perspectiva es imposible pensar en la revolución. tan sólo transformando las relaciones de producción; resulta necesario hacer cambios profundos en el plano de lo ideológico.

El movimiento feminista surge en México en los setenta. Tiene claros puntos de coincidencia con los movimientos de mujeres que se desarrollan en todo el mundo. de los cuales toma ejemplos que adapta a su realidad.

Comenzaron a reunirse para cuestionar su situación marginal y analizar sus experiencias previas en el campo de la política. Se hacen conscientes de que son objeto de discriminación en función de su sexo.

Las integrantes son mujeres pertenecientes a los sectores medios, son universitarias, con una amplia información que les permite conocer lo que sucede con movimientos similares en el extranjero. Son mujeres que, o bien participaron en el movimiento estudiantil del 68 o son compañeras de militantes de partidos o grupos de izquierda, donde sufren la misma marginación de la que son objeto en la sociedad.

Por su extracción social y por su trabajo tienen acceso a los medios de comunicación (prensa), lo cual les permite difundir artículos referentes al movimiento y a la situación de la mujer en México y en el mundo.

Tal es el caso de los artículos de Rosario Castellanos en Excélsior ( 5 de septiembre de 1970) y de Marta Acevedo (30 de septiembre de 1970) en 
Siempre $!^{5}$ en los que a partir de la reseña de la manifestación realizada en Berckeley por el cincuentenario del otorgamiento del voto a la mujer, dan a conocer los planteamientos de las feministas norteamericanas.

Ambos artículos tienen resonancia en el medio universitario, ya que se comienza a plantear en nuestro país la problemática de la vida cotidiana de la mujer. Los grupos que existían se movilizaban solamente alrededor de demandas legales o bien apoyaban las luchas de los hombres al interior de los partidos o grupos políticos integrados o disidentes del sistema.

Mujeres jóvenes, sin una idea precisa sobre cómo organizarse, vieron en el artículo de Siemprel la posibilidad de reunirse a discutir la situación de la mujer. Buscan opciones de participación, desean "reinventar un movimiento", partir de lo ya existente pero tomando en cuenta la especificidad económica y política de nuestro país. La idea es colocar en primera línea del conocimiento público la cuestión de la igualdad sexual y la necesidad de reordenar las relaciones básicas entre hombre y mujer, subvertir la vida cotidiana.

Este fue el punto de partida del nuevo feminismo en nuestro país.

Si bien no es posible periodizar un lapso de 13 años, dado que es un proceso de constitución, escisión y reagrupamiento, con objetivos más o menos semejantes y con tareas más o menos específicas, hemos encontrado momentos diferenciales a lo largo de este tiempo, al igual que ciertos hechos 0 circunstancias que aparecen como hitos en su acontecer.

1970-1974. Durante estos cinco años se constituyen 3 grupos: Mujeres en Acción Solidaria (MAS-1971), Movimiento Nacional de Mujeres (MNM1972) y Movimiento de Liberación de la Mujer (MLM-1974).

Si bien dos de ellos se autodenominan movimiento, ninguno aglutina más de cincuenta mujeres. aunque en sus objetivos figure el intento de convertirlos en movimientos masivos. Son grupos que se proclaman autónomos de partidos, instituciones y organismos del Estado. Grupos de Mujeres y para mujeres con reivindicaciones específicas que atañen a su condición. Sin perder de vista la perspectiva social, tratan de captar a mujeres de las clases subalternas.

Estos intentos no fueron exitosos, sin duda por la extracción de clase de las feministas y por plantear reivindicaciones que para las trabajadoras resultaban a largo plazo. Sin embargo, fue una forma de difundir sus ideas con el objetivo de conformar una nueva conciencia.

Su forma de funcionamiento se basaba en lo que se conoce como "el pequeño grupo", a excepción del MNM que sustenta dentro de sus principios una forma jerarquizada de organización.

Esos pequeños grupos que pretendian un trabajo de carácter horizontal y democrático, en contraposición a las organizaciones de hombres, jerarquizadas y autocráticas, no escaparon de aquello que criticaban. La pugna por la dirección, por la imposición de puntos de vista personales, en suma, la lucha por el poder al interior del grupo, no se hizo esperar.

El problema residió en la existencia de objetivos sumamente amplios y a veces ambiguos (por falta de una teoría general sobre la opresión de la mujer), que a la hora de concretar y establecer líneas de trabajo se enfrentaban con la casi imposibilidad de formularlos. Esto determinaba sesiones interminables de crítica, autocrítica y evaluación, donde la pugna por el poder era

\footnotetext{
5 Marta Acevedo. "Nuestro sueño está en escarpado lugar. (Crónica de un miércoles santo entre mujeres). 'Women's Liberation'. San Francisco", en Siemprel, La Cultura en México. México, septiembre 30, 1970, núm. 451. Rosario Castelłanos, "Casandra de huarache. La liberación de la Mujer... aquí, en Excelsior. México, 5 de septiembre de 1970.
} 
manifiesta, pero al mismo tiempo permitió a la mujer tomar la palabra y aprender una práctica que desconocía y le era ajena.

Las acciones que estos grupos llevaron a cabo presentan diferencias por su misma composición. Movimiento Nacional de Mujeres se abocó a la tarea de revisar libros de texto gratuitos con el fin de denunciar las imágenes sexistas que en ellos aparecían, así como al examen de las leyes discriminatorias para la mujer y a la lucha por el aborto libre y gratuito. No cuestionan la transformación de la estructura social, creen en la liberación individual de la mujer y con ello tratan de lograr reformas tendientes a mejorar la situación femenina, de allí su crítica a la legislación. No hacen un análisis capaz de mostrar que las mujeres, lejos de ser una masa homogénea, están divididas en clases sociales y que la opresión, si bien es sufrida por todas, se expresa diferentemente según la clase social a la que pertenecen.

El MAS Y el MLM, este último escisión del primero, están conformados por mujeres provenientes de la izquierda universitaria, quienes pretendían reelaborar la vinculación entre marxismo y feminismo, que unido al análisis de la realidad nacional fuera capaz de combinar la problemática de la explotación de clases con la opresión de la mujer. Las acciones de estos grupos van desde la difusión a través de publicaciones, conferencias, obras de teatro, cine clubes, etc. a intentos de constitución de una Casa de las Mujeres como centro de reunión y convivencia, tratando de llevar a la práctica sus planteamientos teóricos de solidaridad y hermandad entre ellas.

Un problema de fricción (que será motivo de discusión permanente) es el papel de la mujer ante los partidos de izquierda, donde se les considera sectarias por no participar activamente en los movimientos que irrumpen en esos momentos. Muchas pensaban que el análisis de las relaciones de pareja y familia era fundamental, sin embargo, estas discusiones no se dieron por estar algunas más interesadas en revaluar la forma de establecer una estrategia de lucha a través del análisis en el "pequeño grupo".

1975: Año Internacional de La Mujer. Tiene su origen en una reunión de la Comisión de la Condición Jurídica y Social de la Mujer de Naciones Unidas en 1972. La propuesta original presentada por algunas organizaciones femeninas tuvo como objetivo la igualdad, el desarrollo y la paz. Se consideró que el desarrollo económico y social entrañaba una serie de acciones que exigian la participación de la mujer. La propuesta fue aceptada, siendo México la sede.

Ante la alternativa de participar o no con el Estado en el desarrollo de las actividades que el Año Internacional de la Mujer implicaba, algunas militantes de lo que quedaba del mas colaboraron en la creación del Centro de Información y Documentación para el Decenio de la Mujer y el Desarrollo (CIDDEM). ${ }^{6}$ Este Centro, auspiciado por el Estado, funcionó como compilador, clasificador y difusor de información sobre la mujer en México. Prestaba servicios de biblioteca y era centro de reunión.

Los demás grupos deciden mantenerse al margen y dirigir sus esfuerzos a la organización de un "Contracongreso" para boicotear la reunión, resolución que el Movimiento Feminista Internacional también había tomado. manifestándose en contra y denunciando su carácter manipulador. Pretendían. de esta manera, dar a conocer que había otra posición en el país, que estaban en desacuerdo con la postura oficial.

EI MLM llevó a cabo una serie de actividades tendientes a mostrar que estaban contra el desarrollo del capitalismo y por la transformación del mis-

- Parte del material ahí recopilado se encuentra actualmente en el Centro de Documentación de la Mujer Mexicana del Consejo Nacional de Población (CONAPO). 
mo: contra la igualdad, pues no buscaban la igualdad en la explotación sino el derecho a la diferencia; y contra la paz, porque se consideraban un movimiento en lucha.

El MNM participó en algunas de las actividades del Contracongreso, especialmente en las jornadas por la derogación de las leyes punitivas del aborto.

El trabajo realizado durante este año evidenció que los grupos no habian logrado todo el impacto deseado en la opinión pública. Provocó, además de los conflictos internos que acarreaban, una desmoralización que sirvió de detonante para una escisión más dentro del MLM.

Ante la pugna entre nuevas y viejas feministas surge el Colectivo La Revuelta (1975), nueva agrupación diferente a los grupos ya constituidos: se reduce a 7 miembros; es cerrado, no buscan atraer nuevas militantes y se or: ganizan alrededor de un objetivo: la difusión y publicación de un periódico de mujeres como solución al estancamiento a que se habia llegado. En el primer número denominado también La Revuelta, se manifiestan contra la opresión de la mujer, contra la explotación de que es objeto en la sociedad capitalista, contra toda forma de sexismo; por reivindicaciones posibles de ser arrancadas al sistema (aborto libre y gratuito. guarderías).

Luchan por la disolución de la familia patriarcal, por la socialización del trabajo deméstico y por la verdadera liberación de la mujer y de todos los hombres. ${ }^{7}$ Consideran el feminismo como una práctica política, cotidiana $y$ organizativa.

Estos planteamientos representan una ordenación de las premisas que! los grupos MAS Y MLM habian sostenido.

1976-1983. El año 1976 muestra un descenso en la actividad de los grupos. Surge la opción de integrarse a un trabajo conjunto, a partir de problemas prioritarios en los cuales existe acuerdo: aborto libre y gratuito, protección a la mujer golpeada y contra la violación.

La Coalición de Mujeres Feministas (1976) actúa entonces como elemento cohesionador de las demandas coincidentes de todos los grupos, independientemente de la orientación y objetivos de cada uno de ellos, aglutinándolos alrededor de tareas concretas y específicas.

A los grupos que integraban la Coalición (MNM. MLM. y Colectivo La Revueltal además de los de liberación homosexual ${ }^{8} y$ otros efímeros que surgen y desaparecen, ${ }^{9}$ se les presenta por primera vez la cuestión de la doble militancia ${ }^{10}$ ante la inclusión de un nuevo grupo con características diferentes a los ya existentes: el Colectivo de Mujeres (1976).

Nace a partir de discusiones sostenidas por las militantes del PRT. quienes habían decidido realizar un trabajo de vinculación con mayor número de mujeres. Ante la necesidad de ser consideradas como grupo feminista comienzan a funcionar como grupo de concientización. Las feministas no las aceptaron fácilmente, girando la discusión en torno al grado de autonomía ante la organización partidaria. Sus tareas fueron la lucha por la igualdad de oportunidades en la educación y el trabajo, por salario igual ante igual trabajo. por mayores prestaciones laborales para las madres trabajadoras, al igual que por reivindicaciones en torno a la sexualidad y al aborto libre y gratuito.

El Colectivo se integra a la Coalición de Mujeres y esto acarrea fricciones

ᄀ La Revuelta. México, septiembre 1976. núm. 1.

- El movimiento de Liberación Homoxesual no forma parte de este trabajo

- Un ejemplo lo constituye el Movimiento Feminista Mexicano (MFM).

10 La doble militancia es aquélla que realizan las mujeres cuando pertenecen a un partido político y a un grupo feminista. 
con el partido, ya que no siempre acataron sus lineamientos en relación a la situación de la mujer.

Los diferentes grupos no se disuelven para constituir la Coalición. guardan su idependencia, su autonomía y sus posturas, variaban según la cuestión tratada, presentándose contradicciones.

En este momento aparecen nuevas publicaciones la revista FEM y la Coalición pública CIHUAT.

La Coalición presenta al Congreso la propuesta de ley sobre la despenalización del aborto. Si bien el proyecto es recibido no es objeto de discusión en las Cámaras.

La polémica sobre la doble militancia es uno de los puntos más relevantes en sus debates lo que llevará a algunos de los grupos a realizar alianzas con partidos de izquierda.

“Las contribuciones principales del feminismo se refieren por un lado al señalamiento de que las mujeres sufrimos una opresión específica, particular, que nos abarca a todas, independientemente de la clase social a la que pertenecemos, y por otro, a que es necesario politizar lo personal. Para el feminismo esto significa reconocer la importancia que tiene lo privado (la familia, la reproducción privada de la fuerza de trabajo, las relaciones hombremujer) para el funcionamiento de lo público." 11

Este trabajo conjunto culminará con la constitución del Frente Nacional por la Liberación y Derechos de la Mujer (FNALIDM-1979) que aglutina a varios grupos feministas (MLM. MNM, LF. ${ }^{12}$ Colectivo de Mujeres y GAMU). sindicatos (principalmente los universitarios), y partidos de izquierda (PC $y$ PRT), además de grupos de liberación homosexual.

EI FNALIDM se propone unificar esfuerzos de todas las organizaciones políticas, partidarias, sindicales, feministas y sociales a fin de que las mujeres gocen de todos los derechos en la sociedad. Los puntos en los que centra su lucha son: 1 . maternidad libre y voluntaria: 2 . lucha por guarderías: 3 . contra el hostigamiento y la violencia sexual, y 4 . denuncia contra la situación de mujeres trabajadoras que no gozan de los derechos otorgados por la Ley Federal del Trabajo.

La aparición del Frente determina el debilitamiento de la Coalición al recoger una de sus demandas: la despenalización del aborto, culminando su campaña con un Proyecto de Ley presentado por el grupo Parlamentario Comunista (Coalición de lzquierda).

El Proyecto de Ley sobre Maternidad Voluntaria enfoca la cuestión del aborto como problema de salud que debe ser considerado dentro del marco socio-económico y cultural del país. Afirma que no es suficiente la despenalización del aborto, "las mujeres que reivindican el derecho a la maternidad voluntaria recurren sólo en última instancia al aborto voluntario y gratuito: gratuito, porque debe realizarse como un servicio de los hospitales de Estado:

11 "El Frente Nacional por la Liberación y los Derechos de la Mujer: balance y perspectivas". en Buelna, Sinaloa, UAS, julio 1980, año II, núm. 6, p. 51

12 Lucha Feminista es un nuevo grupo integrado por sicólogas interesadas en los problemas sociales y sus implicaciones en la mujer. Comenzaron con un circulo de estudios por considerar más importante ahondar en la teoria feminista que organizar un grupo de trabajo hacia el exterior, tarea para la cual no se consideraban preparadas. Tienen como objetivos: validar la cuestión femenina ante los partidos de izquierda que en su mayoría la rechazan por considerarla una desviación de la teoría de la lucha de clases: recalcar la importancia del cuerpo de la mujer y de su sexualidad desde una perspectiva política: rescatar la vida cotidiana $y$, por último, evitar la deshumanización de la sociedad y el confinamiento de las mujeres. 
pero la maternidad voluntaria no sólo implica la legalización de la práctica del aborto, pone énfasis en la aplicación de medidas para prevenirlo". ${ }^{13}$

EI FNALIDM llevó a cabo campañas de divulgación y movilización para permear la opinión pública en favor del proyecto, sin embargo los resultados no fueron los esperados, ya que la campaña tuvo una amplia resonancia dividiendo la opinión de los legisladores. El Proyecto fue aceptado.

Con la organización del Frente surge el Grupo Autónomo de Mujeres Universitarias (GAMU-1979). Su objetivo es constituir un movimiento de mujeres en la Universidad capaz de crear conciencia feminista entre los y las estudiantes, con demandas semejantes a la de los otros grupos ya constituidos. Sostiene la autonomía del movimiento enmarcada dentro de la lucha de clases, lo que implica la alianza de las mujeres con sindicatos y partidos en cuyos programas se encuentran reivindicaciones para la mujer. Por lo tanto en GAMU aplican la doble militancia. Funcionan a través del pequeño grupo y de reuniones plenarias de coordinación y discusión política. Organizan conferencias, cine-clubs y movilizaciones a favor de la despenalización del aborto.

Entre tanto. el Frente trató de afirmarse como organización nacional. Pero la pugna entre las diferentes corrientes políticas paraliza el trabajo, dando lugar a que algunos grupos dejen de participar sin retirarse formalmente.

A iniciativa del MLM. LF y Colectivo de Mujeres, se inaugura en 1979 el Centro de Apoyo a la Mujer Violada (CAMV), con el objeto de brindar asesoría legal y ayuda psicológica y médica a las mujeres que allí acuden. Intentan a su vez presionar para que los violadores sean castigados y se modifiquen las leyes en ese sentido.

Militantes del MLM formaron el Colectivo de Acción Solidaria con la Empleada Doméstica (CASED) trabajando en cursos de alfabetización. asesoramiento legal y educación sexual.

La presencia legal en 1981-1982 de partidos de izquierda en la escena política, enfrenta a las feministas en tanto grupos autónomos. ¿Cuál será su actitud en las elecciones? Deciden establecer alianzas con ellos conforme a los intereses de cada grupo. Los partidos de izquierda intentaron atraer a las mujeres en tanto que población políticamente disputable. de la misma manera que el Partido oficial (PRI) incluyó en sus programas reivindicaciones en el mismo sentido. MLM Y LF se unieron al PSUM, mientras GAMU y el Colectivo de Mujeres al PRT.

La intensa labor de difusión llevada a cabo por los grupos genera la reciente tentativa de unificación: la Red Nacional de Mujeres (1982), que pretende lograr el intercambio y la comunicación a nivel nacional sin exigir a cambio su adhesión en torno a líneas comunes de trabajo. El objetivo de la Red, por tanto, es la integración de los grupos feministas a fin de facilitarles canales de apoyo e información útiles en las acciones que cada uno desarrolla.

Durante el año pasado (1983) realizaron actividades en común, abriendo la posibilidad de un trabajo conjunto cuyos resultados son aún difíciles de evaluar.

El movimiento feminista se caracteriza por su lucha contra el poder, contra toda manifestación del mismo. Poder entendido como una relación de fuerza, como proceso donde aparece un elemento dominante y un elemento dominado, que propicia la lucha y el enfrentamiento.

La "astucia" del dominante (por llamarla de algún modo) consistió en organizar un espacio de dominio. un espacio de prácticas que avalen la situación de sometimiento. Este espacio primero es la familia $y$ a partir de ahí la

13 FNALIDM. Resoluciones de la Conferencia Nacional Constitutiva. México. Boletín núm. 1. p. 1 . 
opresión y dominación se extiende al campo de lo social.

Sin embargo, la situación no es unilateral. El dominado siempre resiste, la mujer siempre encontró formas de resistencia, muchas de ellas permitidas $y$ por lo tanto codificadas por el dominador (la manipulación. la histerización de las relaciones, el lloriqueo, etc.). El movimiento feminista adopta otras formas de resistencia no permitidas, genera un saber y un rechazo que le exige al dominador amoldar, al menos, su discurso y a veces su misma práctica. Las mujeres comienzan a producir espacios de sobrevivencia diferentes.

Podemos decir con Foucault ${ }^{14}$ que "donde hay poder hay resistencia". Esta desempeña papeles diferentes según la situación estratégica en que se encuentren en ese momento las relaciones de poder. Puede ser de adversario, de blanco de ataque, de apoyo, o bien de paradigma de resistencia; es también la forma en que responde el dominador.

No debemos pensar la resistencia como una forma única o unívoca, sino múltiple, variable, móvil, que se da por diferentes flancos, a veces violenta, otras pasiva. No importa las caracteristicas que asuma, siempre en mayor o menor medida rompen, descodifican, quiebran e introducen líneas de fractura en la dominación; al tiempo que suscitan nuevos reagrupamientos y abren espacios.

El movimiento feminista tiene como táctica producir espacios de sobrevivencia cada vez más amplios, verdaderos islotes de resistencia. Esta producción determina, en el plano del pensamiento, avances irreversibles.

Resumir las características del movimiento feminista en México desde esta perspectiva nos otorga una visión diferente:

- es un movimiento inorgánico. Sin duda le faltan elementos cohesionadores y una dirección. Peyorativamente se ha dicho que son mujeres que, por falta de otra actividad, igritan! ¿No deberiamos acaso preguntarnos sobre la eficacia de ese grito? En este tiempo, ¿qué ha significado? Se afirma en todos los campos, se hace oír, establece discontinuidades. Inició una guerra en el plano de las ideas, guerra asumida como tal, ya que se autodenominan "mujeres en lucha":

- funciona con el "pequeño grupo". Grupos de amigas que intentan hermanarse y solidarizarse entre sí, grupos que aparecen y desaparecen. grupos que se escinden y se conforman nuevamente, mujeres que circulan de un grupo a otro. Despectivamente se piensa que nada puede esperarse de mujeres con tan poca consistencia. ¿Dónde están sus logros? , siempre observadas desde un punto de vista productivista y finalista.

Sin embargo tendríamos que preguntarnos ¿hacia dónde conduce ese poner en duda, ese intento de transformarse y transformar? Podríamos responder con Guattari que luchan en el frente del deseo, ya que "la lucha revolucionaria no podría circunscribirse solamente al nivel de las relaciones de fuerza aparentes. Debe desarrollarse igualmente en todos los niveles de la economía deseante que están contaminados por el capitalismo len el nivel del individuo, de la pareja, de la familia, de la escuela, del grupo militante, de la locura, de las prisiones, de la homosexualidad, etc. ${ }^{\prime \prime} .15$

Esta subversión de todos los poderes en todos los niveles ha sido por momentos recuperada. Las mujeres que integran el movimiento han quedado muchas veces aprisionadas en ese sistema de pensamiento que legitima y encubre la dominación. La recuperación se dio en diferentes ámbitos y por vías disímiles:

14 Michel Foucault, Historia de la sexualidad, México. Siglo XXI, 1978, p. 116.

15 Gilles Deleuze y Félix Guattari, Op. Cit., p. 11. 
- recuperación por el sistema en su conjunto. Algunos grupos repitieron prácticas que no hicieron más que reproducir el sometimiento. En vez de subvertir el orden se integraron, en vez de transformar la sociedad reforzaron la existente;

- recuperación por parte del Estado. "Se prepara quizás el terreno para la creación de una Secretaría de Estado de la Condición Femenina y quizás también en un futuro no muy lejano, se extienda el proceso de corporativización de la sociedad mexicana al sector femenino y se integre como tal dentro del partido oficial. A esto llamamos recuperación. $Y$ esto facilitamos cuando, cargadas de buenas intenciones, nos integramos con nuestros proyectos a las instituciones, o pretendemos utilizar ciertas plataformas que representan intereses radicales opuestos a los nuestros"; 18

- recuperación por los partidos de izquierda, quienes se manifestan contra la autonomía del movimiento feminista. Consideran que las cuestiones que plantean las mujeres son de orden secundario, que deben unirse a la lucha partidaria contra la contradicción (para ellos) "principal" (capital-trabajo). Parece que sólo les interesan militantes y votos.

Podemos finalmente interrogarnos sobre las perspectivas del movimiento feminista en México. No es ésta una pregunta neutra, analizaremos las perspectivas en función de metas y objetivos globales de cambio y transforma. ción de la sociedad.

A partir de estas consideraciones observamos que el movimiento feminista ha recorrido un camino y vemos sus avances:

- aparecen grupos en provincia que insuflan aires nuevos al movimiento. Hasta hace muy poco la provincia no participaba en las discusiones a nivel nacional, todos los grupos eran de la capital. Por primera vez tiene lugar una reunión nacional en Colima (1983):

- ericontramos cada día mayor número de mujeres independientes de partidos $y$ de grupos feministas constituidos que se reúnen para realizar tareas concretas y específicas, que no adoptan un nombre ni buscan ser reconocidas como grupo, pero que sin embargo se hacen presentes;

- se crean centros de estudio sobre la mujer a nivel académico lo cual indica un reconocimiento de la cuestión en el medio universitario como problema científico y académico. ${ }^{17}$

El discurso feminista ha ido permeando diferentes ámbitos y distintas clases, adquiere derecho de existencia, se legitima:

- alcanza su mayor fuerza en las mujeres de los sectores medios, principalmente universitarias, profesionistas, quienes encuentran que las reivindicaciones feministas les atañen directamente; no se adhieren a la lucha de otra clase, sino que es su propia lucha;

- siendo esta problemática de carácter mundial, inscrita en el proceso de "modernización", permea el discurso del Estado. Este debe dar una respuesta, que si bien es evidente en el discurso, no es asi en la práctica:

- las clases subalternas comienzan a sentir el impacto de estas voces. Mujeres obreras, colonas, burócratas, aunan a sus demandas reivindicaciones específicas en tanto mujeres.

La cuestión ya no puede ser olvidada ni desconocida, y si así fuese, alguien que pertenezca al $50 \%$ de la humanidad alzará su voz, para recordarlo.

16 Eli Bartra, Op. Cit., pp. 6-7. Valga mencionar el papel desempeñado por el Programa Nacional para la integración de la Mujer al Desarrolio (PRONA). dependiente de CONAPO

17 La UNAM, la UAM. El Colegio de México, etcétera. 
El movimiento feminista es un movimiento que lucha por la destrucción del capitalismo, no en el frente económico, contra la explotación, sino en el frente del deseo, contra el poder y la opresión.

"...si se lucha contra el poder, entonces todos aquéllos sobre los que se ejerce el poder como abuso, todos aquéllos que lo reconocen como intolerable, pueden comprometerse en la lucha allí donde se encuentra y a partir de su actividad (o pasividad) propia. Comprometiéndose en esta lucha que es la suya, de la que conocen perfectamente el blanco y de la que pueden determinar el método, entran en el proceso revolucionario. Como aliados ciertamente del proletariado ya que, si el poder se ejerce tal como se ejerce, es ciertamente para mantener la explotación capitalista. Sirven realmente la causa de la revolución proletaria luchando precisamente allí donde la opresión se ejerce sobre ellos...

"Estas luchas forman parte actualmente del movimiento revolucionario, a condición de que sean radicales, sin compromisos ni reformismos, sin tentativas para modelar el mismo poder consiguiendo como máximo un cambio de titular. $Y$ estos movimientos están unidos al movimiento revolucionario del proletariado mismo en la medida en que él ha de combatir todos los controles e imposiciones que reproducen en todas partes del mismo poder."18 